\title{
DETERIORAÇÃO DE ÓLEOS VEGETAIS EXPOSTOS A DIFERENTES CONDIÇÕES DE ARMAZENAMENTO
}

\author{
Deterioration of vegetable oils exposed to different conditions of storage \\ Sérgio Thode Filho', Gabrielle Borges Cabral², Fabíola da Silveira Maranhão², \\ Marcelo Fonseca Monteiro de Sena ${ }^{4}$, Elmo Rodrigues da Silva ${ }^{5}$ \\ 'Doutorando em Meio Ambiente pelo PPG-MA da Universidade do Estado do Rio de Janeiro - UERJ, Professor do Instituto Federal de Educação, \\ Ciência e Tecnologia do Rio de Janeiro - IFRJ, Campus Duque de Caxias, RJ, Laboratório Multidisciplinar de Gerenciamento de Resíduos - LMGR \\ ${ }^{2}$ Aluna do Curso de Bacharel em Química IFRJ, bolsista pesquisadora do LMGR \\ ${ }^{3}$ Técnica em Polímeros IFRJ, bolsista pesquisadora do LMGR \\ ${ }^{4}$ Professor do Instituto Federal do Rio de Janeiro - IFRJ, Campus Duque de Caxias, RJ - LMGR \\ ${ }^{5}$ Professor do PPG-MA da Universidade do Estado do Rio de Janeiro - UERJ
}

\begin{abstract}
Resumo
A qualidade final de um óleo depende de todas as etapas envolvidas na produção do mesmo. Estas etapas incluem desde o cultivo, a extração, o refino, o transporte, a distribuição e a comercialização dos óleos. Os processos de oxidação em alimentos são responsáveis pela redução da vida na prateleira das matérias-primas e dos produtos industrializados levando a importante perda econômica. O objetivo deste trabalho foi analisar os índices de acidez e peróxido de óleos vegetais virgens de soja, milho, canola e girassol, submetidos a diferentes condições de armazenamento antes do consumo. O procedimento para verificação do índice de acidez e peróxido foi executado com base na metodologia do Instituto Adolf Lutz (2004). Ao final do período de análise, todos os óleos do grupo exposto apresentavam índice de acidez e peróxido superiores ao do grupo guardado. O óleo de soja mostrou-se o óleo mais estável para se trabalhar em relação aos índices avaliados, seguido do óleo de girassol. Apesar do óleo de canola apresentar baixos teores de ácidos graxos saturados, esta pesquisa revelou que o canola é um óleo extremamente sensível em relação a sua estabilidade físico- química quando exposto a luz e a temperatura.
\end{abstract}

Palavras-chave: Óleo vegetal, acidez, peróxido, foto oxidação.

\begin{abstract}
The final quality of the oil depends on all the stages of the production. These steps range from the cultivation, extraction, refining, transportation, distribution and marketing of oils. Oxidation processes in foods are responsible for reducing shelf life of raw materials and manufactured products leading to major economic loss. The objective of this study was to analyze the levels of acidity and peroxide virgin vegetable oils from soy, corn, canola and sunflower undergo under different conditions of storage before consumption. The procedure for checking the index of acidity and peroxide was conducted based on the methodology of the Adolfo Lutz Institute (2004). At the end of the analysis period, all oil exposed group had higher acid value and peroxide to the saved group. Soybean oil was found to be the most stable oil to work in relation to the indices evaluated, followed by sunflower oil. Despite the canola oil have low levels of saturated fatty acids, this research showed that canola oil is an extremely sensitive regarding their physicochemical stability when exposed to light and temperature.
\end{abstract}

Keywords: Vegetable oil, acidity, peroxide, photo oxidation. 


\section{INTRODUÇÃO}

As propriedades físicas e químicas de um óleo estão relacionadas principalmente com a sua composição em ácidos graxos, com o grau de insaturação e posição destes na molécula de glicerol e com o comprimento da cadeia carbônica dos mesmos. A diferença entre uma gordura e um óleo está no estado físico em temperatura ambiente, isto é, uma gordura é um sólido e um óleo é um líquido geralmente, as gorduras sólidas são indicadas por um maior índice de ácidos graxos saturados, e os líquidos por um alto nível de ácidos graxos insaturados (O'BRIEN, 2000; WHITE, 2000).

Os processos de oxidação em alimentos são responsáveis pela redução da vida de prateleira das matérias-primas e dos produtos industrializados levando a importante perda econômica. A rancidez ocorre principalmente durante o processamento de armazenagem e resulta em alterações dos principais parâmetros de qualidade como a cor, produção de compostos voláteis responsáveis pela formação de sabores e odores desagradáveis. As principais alterações químicas que ocorrem nos óleos vegetais são por processos químicos como a auto-oxidação, a polimerização térmica ou a oxidação térmica, que podem ser acelerados pelo calor, luz (foto-oxidação), ionização, traços de metais ou catalisadores (DEGÁSPARI \& WASZCZYNSKYJ, 2004; NOGALA-KALUCKA et al., 2005; MALLÉGOL, 2000). Portanto, este trabalho torna-se relevante, uma vez que foram observados poucos estudos a esse respeito na literatura científica. $\mathrm{O}$ objetivo deste trabalho foi analisar os índices de acidez e peróxido de óleos vegetais virgens (soja, milho, canola e girassol), submetidos a diferentes condições de armazenamento antes do consumo.

\section{METODOLOGIA}

Os experimentos e armazenagem do material foram realizados no município de Duque de Caxias, RJ, no Laboratório Multidisciplinar de Gerenciamento de Resíduos do Instituto Federal de Educação, Ciência e Tecnologia do Rio de Janeiro. No supermercado A, foram adquiridas oito garrafas de $1000 \mathrm{ml}$ dos óleos de soja, milho, canola e girassol, do mesmo fabricante e lote de produção. Lote de fabricação 16.08 .13 e validade 12.02.13. Após aquisição do óleo no estado virgem, as oito garrafas foram dividas em dois grupos: (I) Guardado; e (II) Exposto. O grupo I consistiu em separar uma embalagem de $1000 \mathrm{ml}$ de cada categoria escolhida (soja, milho, canola e girassol) e armazená-lo dentro de um armário fechado, a temperatura ambiente e na ausência total de luz por um período de oito semanas. Os óleos do grupo II só entravam em contato com a luz por no máximo cinco minutos, nos dias estabelecidos no cronograma de trabalho, para coleta das massas necessárias para análise. O grupo II ficou então exposto na prateleira do Laboratório Multidisciplinar de Gerenciamento de Resíduos. As embalagens do grupo II foram totalmente expostas à luz ambiente do laboratório e ao meio. A temperatura média nos dois meses de análise foi de $30^{\circ} \mathrm{C}$. A compra do material foi realizada no dia 16/10/2013 e foram feitas as análises de acidez e peróxido nos óleos do grupo I e grupo II no mesmo dia. A cada duas semana, a partir da data de compra procedeu-se a avaliação dos referidos índices.

O procedimento para verificação do índice de acidez e peróxido foi executado com base na metodologia do Instituto Adolf Lutz (2004). Para determinação do índice de acidez das amostras, estas foram homogeneizadas no estado líquido e pesadas $2 \mathrm{~g}$ para cada amostra, em Erlenmeyer de $125 \mathrm{ml}$. Foi adicionado $25 \mathrm{ml}$ de solução éter-álcool (2:1) neutra, e após, adicionou-se 2 gotas de indicador fenoftaleína, onde então a amostra foi titulada com solução de hidróxido de sódio $0,1 \mathrm{~N}$ até o aparecimento da coloração rósea, a qual indica que a solução titulada está neutra. $\mathrm{O}$ cálculo de acidez é determinado pela fórmula:

$$
\mathrm{IA} \%=\mathrm{v} \times \mathrm{f} \times 100 \times 0,0282 / \mathrm{P}
$$

Onde: IA $\%$ = índice de acidez em porcentagem; v= volume de solução de hidróxido de sódio $0,1 \mathrm{~N}$ gasto na titulação; $\mathrm{f}=$ fator de correção hidróxido de sódio $0,1 \mathrm{~N} ; \mathrm{p}=$ número de gramas da amostra.

Foram realizadas as determinações de peróxido em todas as amostras coletadas através do método de titulação da AOCS (1993); onde as amostras foram transferidas para um frasco Erlenmeyer de $125 \mathrm{ml}$ e então adicionado $30 \mathrm{ml}$ de solução ácido acético-clorofórmio (3:2), em seguida, agitado e logo após adicionado $0,5 \mathrm{~mL}$ de solução saturada de iodeto de potássio, deixando em repouso por 1 minuto. Após o repouso foi adicionado $30 \mathrm{ml}$ de água e $0,5 \mathrm{~mL}$ de solução indicadora de amido, onde as amostras que possuíam alterações químicas, como presenças de peróxidos ficaram com a coloração escura. Após obter a cor 
pela presença do indicador de amido, a solução foi titulada com solução de tiossulfato de sódio $0,1 \mathrm{~N}$, até que a coloração escura desaparecesse. Através do método utilizado para determinação do peróxido, foram retirados os valores de peso da amostra, número de $\mathrm{ml}$ da solução de tiossulfato de sódio $0,1 \mathrm{~N}$ gasto na titulação, número de $\mathrm{ml}$ da solução de tiossulfato de sódio $0,1 \mathrm{~N}$ gasto na titulação do branco, a normalidade da solução de tiossulfato de sódio e o fator da solução de tiossulfato de sódio. Com estes dados foi possível verificar o índice de peróxido das amostras em meq por $1000 \mathrm{~g}$ da amostra, através da fórmula:

$$
\text { Ipmeq } / \mathrm{kg}=(\mathrm{A}-\mathrm{B}) \times \mathrm{N} \times \mathrm{f} / \mathrm{P}
$$

Onde: $\mathrm{Ipmeq} / \mathrm{kg}=$ índice de peróxido em mil equivalentes por kilograma de amostra; $\mathrm{A}=$ volume em $\mathrm{ml}$ da solução de tiossulfato de sódio $0,1 \mathrm{~N}$ gasto na titulação; $\mathrm{B}=$ volume $\mathrm{em} \mathrm{ml}$ da solução de tiossulfato de sódio $0,1 \mathrm{~N}$ gasto na titulação do branco; $\mathrm{N}=$ normalidade da solução de tiossulfato; $\mathrm{f}=$ fator da solução de tiossulfato de sódio; $\mathrm{P}=$ peso em gramas da amosta.

\section{RESULTADOS E DISCUSSÃO}

A Figura 1a-d apresenta o resultado dos índices de acidez dos óleos de milho, canola, soja e girassol, respectivamente, dos grupos exposto e guardado.

\section{I Acidez do óleo de milho}

O óleo de milho que iria compor o grupo guardado apresentou um índice de acidez de $0,3474 \%$ na primeira medição realizada no dia 14 de novembro de 2013 e o óleo de milho que iria compor o grupo exposto com índice de $0,2594 \%$. Tal variação se deve a situações de armazenagem e manuseio anteriores à pesquisa. $\mathrm{Na}$ segunda avaliação, a acidez do milho no grupo guardado passou para $0,3909 \%$ e no grupo exposto para $0,4308 \%$. Nota-se, que a partir do momento em que um exemplar do óleo de milho passou ser guardado, o mesmo apresentou um aumento de $30 \%$ em relação a sua acidez inicial, enquanto o óleo que ficou exposto o ultrapassou, já na segunda medição, chegando a aumentar mais de $110 \%$ no final do período de análise, em relação à acidez avaliada inicialmente. Na última medição, a diferença entre grupo exposto e o guardado, no final do período de análise, foi de $0,0950 \%$.

\subsection{Acidez do óleo de canola}

No momento da primeira análise, verificou-se que o óleo de canola que ficaria exposto apresentava uma acidez maior que o óleo de canola que ficaria guardado $(0,2233 \%$ para o óleo exposto e $0,1897 \%$ para o óleo guardado). O óleo guardado apresentou um crescimento maior entre a primeira e a segunda medição, entretanto da segunda à última o mesmo cresceu menos e linearmente. Já o óleo que ficou exposto teve um crescimento pequeno até a quarta medição $(0,2575 \%)$, apresentando um crescimento significativo na quinta medição $(0,4560 \%)$ e na última $(0,5861 \%)$. Percebe-se uma diferença significativa na medição final. No final de dois meses a amostra que permaneceu exposta apresentou uma variação de cerca de $265 \%$, enquanto isso, o exemplar que manteve-se guardado teve um aumento de $215 \%$ no índice de acidez. Na última medição, a diferença entre grupo exposto e o guardado no final do período de análise foi de $0,1770 \%$.

\subsection{Acidez do óleo de soja}

O óleo de soja que compôs o grupo guardado começou a primeira medição com acidez de 0,2017\% e o óleo do grupo exposto com acidez de $0,2617 \%$. Entre a quarta e quinta medições houve um crescimento significativo da acidez medida no óleo guardado, o índice aumentou de 0,4192\% para $0,5376 \%$. Com isso, no final do período de análise, a amostra guardada apresentou uma diferença de $219,5 \%$ no índice de acidez, e a do grupo exposto variou $262 \%$. Na última medição, a diferença entre grupo exposto e o guardado no final do período de análise foi de $0,0463 \%$.

\subsection{Acidez do óleo de girassol}

No momento da primeira análise, o óleo de girassol que ficaria exposto iniciou a primeira medição com uma acidez maior que a do óleo de girassol do óleo que ficaria guardado, $0,2560 \%$ para o primeiro e $0,1824 \%$ para a amostra guardada. Entre a segunda e a terceira medições houve um crescimento na acidez do óleo guardado e um decréscimo na acidez do óleo exposto, o que os aproximou bastante. Porém, a partir da terceira medição o crescimento da acidez do óleo exposto foi superior à do óleo guardado, o que aumentou a diferença entre a acidez final de ambos. $\mathrm{Na}$ última medição, a diferença entre grupo exposto e o guardado no final do período de análise foi de $0,1105 \%$. Para as análises de índice de acidez utilizou-se como referência o valor máximo de $0,9 \%$ de ácido graxo livre, segundo informe técnico da 

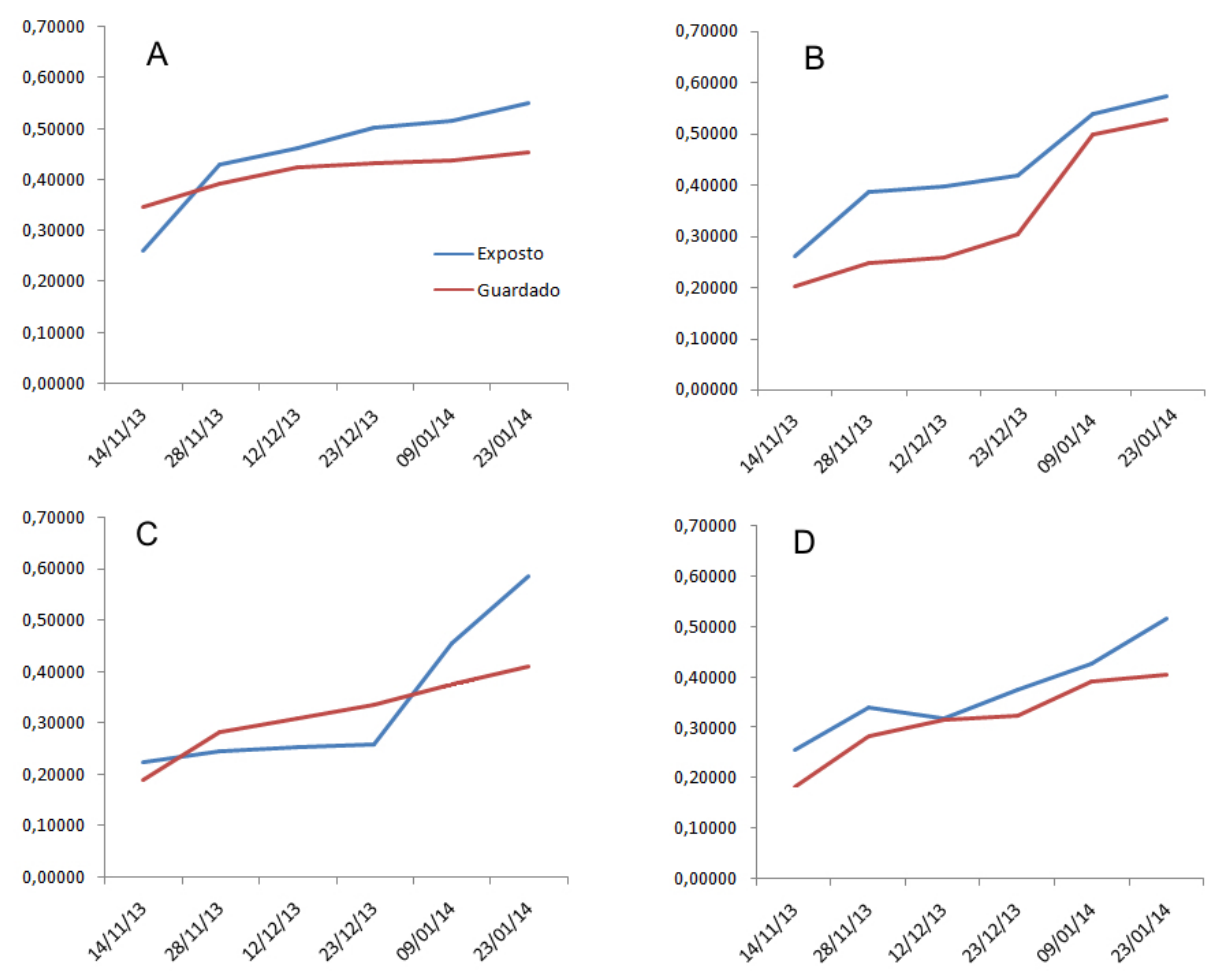

Figura 1. Resultado dos índices de acidez (eixo y) com relação ao tempo (eixo x) dos óleos de milho (A), canola (B), soja (C) e girassol (D) mantidos em condições de exposição à luz (exposto) e na ausência de luz (guardado).

ANVISA referente a óleos e gorduras utilizados em fritura (BRASIL, 2004).

A Figura 2 a-d apresenta o resultado dos índices de acidez dos óleos de milho, canola, soja e girassol, respectivamente, dos grupos exposto e guardado.

\subsection{Peróxido do óleo de milho}

O óleo de milho que iria compor o grupo guardado apresentou um índice de peróxido de $0,8204 \mathrm{meq} / \mathrm{kg}$ na primeira medição realizada no dia 14 de novembro de 2013 e o mesmo óleo de milho que iria compor o grupo exposto com índice de $0,4604 \mathrm{meq} / \mathrm{kg}$. Tal variação se deve a situações de armazenagem e manuseio anteriores à pesquisa. O índice de peróxido do milho apresentou-se maior na primeira medição do óleo exposto em relação ao óleo que ficaria guardado. Ambos apresentaram um crescimento em taxas próximas até a quarta medição, onde o óleo exposto passou a ter um crescimento mais acelerado. Entre a quinta e sexta medições o óleo guardado apresentou dados particularmente constantes. Na última medição, o grupo exposto estava com um índice 2,3294meq/ $\mathrm{kg}$ e o grupo guardado $0,9352 \mathrm{meq} / \mathrm{kg}$. Observou-se uma diferença de $290 \%$ maior que a diferença inicial entre os óleos exposto e guardado. $\mathrm{Na}$ última medição, a diferença entre grupo exposto e o guardado no final do período de análise, foi de $1,3942 \mathrm{meq} / \mathrm{kg}$.

\subsection{Peróxido do óleo de canola}

O óleo que ficaria guardado apresentou na primeira medição um índice de peróxido de $0,3161 \mathrm{meq} / \mathrm{kg}$ e o óleo que ficaria exposto com 0,7888meq $/ \mathrm{kg}$. Percebe-se, na primeira avaliação, um índice inferior do óleo guardado em relação ao exposto. Ambos apresentaram ritmo de crescimento semelhante até a quarta medição, onde o óleo exposto passou a ter um crescimento mais acelerado e na última medição apresentou índices bem superiores ao óleo guardado, com uma diferença de $150 \%$, maior que a diferença inicialmente apresentada entre eles. Dentre as amostras analisadas, o óleo de canola do grupo exposto foi o que exibiu pior desempenho nos testes. $\mathrm{Na}$ última medição, a diferença entre grupo exposto e o guardado no final do período de análise foi de $1,1698 \mathrm{meq} / \mathrm{kg}$.

\subsection{Peróxido do óleo de soja}

O óleo que ficaria guardado, na primeira medição apresentava um índice de peróxido de $0,7586 \mathrm{meq} / \mathrm{kg}$ superior ao óleo que permaneceria 
exposto com $0,1882 \mathrm{meq} / \mathrm{kg}$. Observa-se que no óleo exposto o crescimento é bem maior entre a primeira e segunda medições e nas próximas seu crescimento é menor, com um ritmo próximo ao óleo guardado, porém variou seu índice de peróxido em mais de $1,33 \mathrm{meq} / \mathrm{kg}$, no grupo exposto, entre a primeira e última medições. A tendência do índice de peróxido para ambos os grupos é de um lento crescimento a longo prazo, diferente dos outros tipos de óleo analisados. Essa diferença pode ser atribuída à alta concentração de ácidos graxos saturados. O óleo de soja, dentre os tipos de óleo analisados é o que possui a maior quantidade de ácidos graxos em \% na sua composição, isso confere ao material maior resistência, uma vez que os ácidos graxos saturados são mais estáveis que os insaturados. Na última medição, a diferença entre grupo exposto e o guardado no final do período de análise foi de $0,5988 \mathrm{meq} / \mathrm{kg}$.

\subsection{Peróxido do óleo de girassol}

O óleo exposto já iniciou a primeira medição com um índice de $0,7872 \mathrm{meq} / \mathrm{kg}$ e o óleo guardado com $0,4714 \mathrm{meq} / \mathrm{kg}$. Ambos os óleos apresentam gráficos com ritmo de crescimento muito próximo entre as medições, mantendo praticamente igual a diferença entre seus níveis de peróxido na primeira e última medições. $\mathrm{O}$ exposto exibiu a variação de $295 \%$ no índice de peróxido, enquanto que a amostra do grupo guardado apresentou $420 \%$ de aumento no mesmo. $\mathrm{Na}$ última medição, a diferença entre grupo exposto e o guardado no final do período de análise foi de $0,3408 \mathrm{meq} / \mathrm{kg}$. Para as análises de índice de peróxido utilizou-se como referência o valor máximo de $10 \mathrm{meq} / \mathrm{kg}$, estabelecido pela ANVISA referente a óleos e gorduras refinadas (BRASIL, 2004).

Em tempos modernos, a maioria dos óleos vegetais comercializados no Brasil são envasados em embalagens PET (tereftalato de etileno). Apesar de desempenharem o papel de uma boa barreira física contra o oxigênio e odores, o produto fica mais exposto à luz ambiente, além de permitir a alta permeabilidade ao vapor d'água, o que pode afetar a estabilidade oxidativa do óleo (TAWFIK; HUYGHEBAERT, 1999; DATAMARK, 2006).

A qualidade final de um óleo depende de todas as etapas envolvidas na produção do mesmo. Estas etapas incluem desde o cultivo, a extração, o refino, o transporte, a distribuição e a comercialização dos óleos. Vários estudos têm utilizado métodos acelerados para a avaliação da estabilidade oxidativa de óleos comestíveis, mostrando-se muitas vezes, inadequados por não refletir a realidade do processo oxidativo e pela dificuldade de relacionar os resultados destes testes com a vida de prateleira do produto (OETTERER et al., 2006).
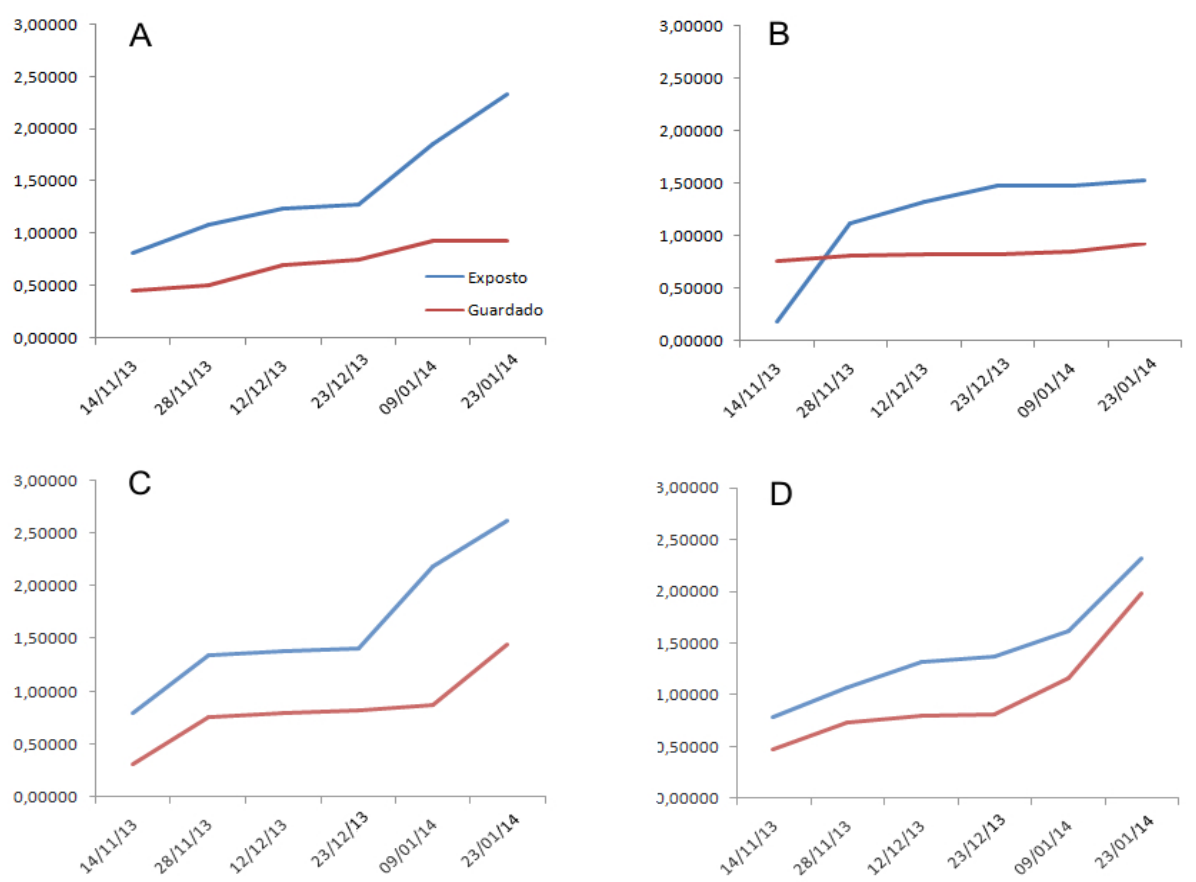

Figura 2. Resultado dos índices de peróxido (eixo y) com relação ao tempo (eixo x) dos óleos de milho (A), canola (B), soja (C) e girassol (D) mantidos em condições de exposição à luz (exposto) e na ausência de luz (guardado). 
A autoxidação ocorre basicamente quando as duplas ligações dos ácidos graxos insaturados da molécula de gordura reagem com o oxigênio atmosférico. É uma reação quase espontânea favorecida por altas temperaturas, incidência de luz, presença de metais pró-oxidantes e grande concentração de duplas ligações (SHERWIN, 1978).

A fotoxidação é a reação direta da luz ativada e do oxigênio com ácidos graxos insaturados formando hidroperóxidos. Ela ocorre devido à presença de moléculas fotossensíveis (clorofila, mioglobina, riboflavina e outros) que podem absorver energia luminosa de comprimento de onda na faixa do visível e na região da radiação ultravioleta (WANASUNDARA; SHAHIDI, 2005).

$O$ índice de acidez revela o estado de conservação do óleo, visto que a decomposição dos glicerídeos é acelerada pelo aquecimento e pela luz, a rancidez é quase sempre acompanhada pela formação de ácido graxo livre. A acidez livre de uma gordura não é uma constante ou característica, mas é uma variável relacionada com a natureza, qualidade da matéria-prima, grau de pureza da gordura, com o processamento e, principalmente, com as condições de conservação do óleo (FARHOOSH et al., 2009).

\section{CONCLUSÃO}

Ao final do período de análise, todos os óleos do grupo exposto, apresentavam índice de acidez e peróxido superiores ao grupo guardado. Para realização das medições a cada duas semanas, os óleos vegetais de ambos os grupos eram abertos individualmente para retirada da amostra necessária para avaliação. O tempo de exposição de cada óleo ao oxigênio, após abertura, era de aproximadamente um minuto. Verifica-se que tal procedimento reproduz o que ocorre em domicílios, bares e restaurantes quando se abre a tampa da embalagem para uso. O óleo de soja mostrou-se o óleo mais estável para se trabalhar em relação aos índices avaliados, seguido do óleo de girassol. O óleo de milho ocupa a terceira colocação, seguido do canola. Apesar do óleo de canola apresentar baixos teores de ácidos graxos saturados, esta pesquisa revelou que o canola é um óleo extremamente sensível em relação a sua estabilidade físico-químicas quando exposto a luz e a temperatura. Esta vulnerabilidade pode estar associada a altas concentrações de ácidos graxos insaturados, isto é, compostos instáveis, devido às duplas ligações presentes nas cadeias carbônicas.
Recomenda-se uma atenção ao armazenar o óleo utilizado, pois fatores físicos como a luz e a temperatura ambiental de exposição desestabilizaram todos os grupos de óleos vegetais estudados. Adicionalmente, recomenda-se que o consumidor verifique o lote de fabricação e validade do óleo vegetal antes da compra, uma vez que, durante o período de análise, os óleos vegetais ainda encontravam-se dentro do prazo de validade. Neste sentido, verifica-se que as embalagens plásticas que armazenam o óleo vegetal não são capazes de manter a integridade físico-química do material até o momento do consumo. Conclui-se que, quanto maior for o tempo de exposição dos óleos à luz e a variações de temperatura, maior será o aumento destes índices estudados.

\section{REFERÊNCIAS}

BRASIL, ANVISA, Agência Nacional de Vigilância Sanitária, 2004.

DATAMARK, 2006. Disponível em <http:/www. datamark.com.br>. Acesso em 03 de janeiro de 2011.

DEGÁSPARI, C.H.; WASZCZYNSKYJ, N. (2004) Propriedades antioxidantes de compostos fenólicos. Visão Acadêmica, (5) 1, 33-40.

FARHOOSH, R.; EINAFSHAR, S.; SHARAYEI, P. (2009) The effect of commercial refining steps on the rancidity measures of soybean and canola oils. Food Chemistry, Mashhad, (115), 933-938.

INSTITUTO ADOLFO LUTZ. Métodos físico-químicos para análise de alimentos. 4 Ed., 1 Ed. digital. São Paulo: 2004.

MALLÉGOL, J.; LEMAIRE, J.; GARDETTE, J. L. (2000) Drier Influence in the curing of linseedoil. Progress in Organic Coatings, London, (39) 2, 107 $-113$.

NOGALA-KALUCKA, M., KORCZAK, J., DRATWIA, M., LAMPSRT-SZCZAPA, E., SIGER, A. e BUCHOWSKI, M. (2005) Changes in antioxidant activity and free radical scavenging potential of rosemary extract and tocopherols in isolated rapeseed oil triacylgliycerols during accelerated tests. Food Chemistry, (93), 227-235.

O'BRIEN, R.D., FARR, W.C., WAN, P.J. Introduction to fats and oils technology. ed. Champaign: AOCS Press, 2000. 
OETTERER, M.; REGITANO-D'ARCE, M.;

SPOTO, M. (2006) Fundamentos de ciência e tecno-

logia de alimentos. Barueri (SP): Manole, 196-351.

SHERWIN, E.R. Antioxidants for vegetable oils. (1978) Journal of the American Oil Chemist's Society, (53) 6, 430 - 436.

TAWFIK, M. S.; HUYGHEBAERT, A. (1999) Interaction of packaging materials and vegetable oils: oil stability. Food Chemistry, Ghent, (64), 451-459.

WANASUNDARA, P.K.P.D.; SHAHIDI, F. (2005)

Antioxidants: Science, Technology, and Applications. In: SHAHIDI, F. Bailey's Industrial Oil and Fat Products: Chemistry, Properties and Health Effects. EUA, Wiley - interscience, (1) 6, cap.11.

WHITE, P.J. Flavor quality of fats and oils. In: O'BRIEN, R.D., FARR, W.C., WAN, P.J. Introduction to fats and oils technology. 2.ed. Champaign: AOCS Press, 2000. 